\title{
Mobile Authoring of Open Educational Resources as Reusable Learning Objects
}

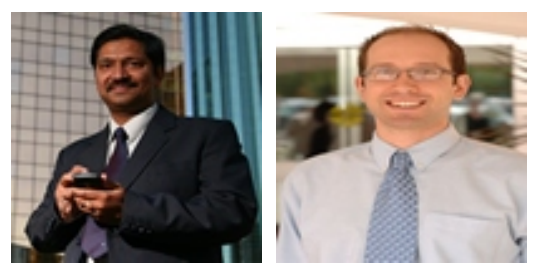

Dr Kinshuk and Ryan Jesse Athabasca University, Canada

\section{Abstract}

E-learning technologies have allowed authoring and playback of standardized reusable learning objects (RLO) for several years. Effective mobile learning requires similar functionality at both design time and runtime. Mobile devices can play RLO using applications like SMILE, mobile access to a learning management system (LMS), or other systems which deploy content to mobile learners (Castillo \& Ayala, 2008; Chu, Hwang, \& Tseng, 2010; Hsu \& Chen, 2010; Nakabayashi, 2009; Zualkernan, Nikkhah, \& Al-Sabah, 2009). However, implementations which author content in a mobile context do not typically permit reuse across multiple contexts due to a lack of standardization. Standards based (IMS and SCORM) authoring implementations exist for non-mobile platforms (Gonzalez-Barbone \& Anido-Rifon, 2008; Griffiths, Beauvoir, Liber, \& Barrett-Baxendale, 2009; Téllez, 2010; Yang, Chiu, Tsai, \& Wu, 2004). However, this paradigm precludes capturing learning where and when it occurs. Consequently, RLO authored for e-learning lack learner generated content, especially with timely, relevant, and location aware examples.

Keywords : Open education resources; reusable learning objects; mobile technology 


\section{Introduction}

The tool presented in this article fits within the definition of open educational resource initiatives which includes open content, open software tools (e.g., learning management systems or authoring tools), and repositories of learning objects (Downes, 2007). Moreover, experts have suggested "that adopting a learning design methodology may provide a vehicle for enabling better design and reuse of Open Educational Resources (OER)" (Conole \& Weller, 2008, p. 1); thus provisioning of tools to author learning designs, like the one presented in this article, can improve adoption of OER for content creation and subsequent reuse. The learning objects created within the subject tool can be considered an open, technology and format specific subset of an OER (Friesen, 2009).

At the macro level, this system allows learners to create OER to be shared under social constructivism. At the meso level, this article presents a framework for the development of an implementation for assembly and creation of OER. At the micro level, the system can author learning design which can be used for instructional design within an OER. Additionally, new information technology developments enable the creation of OER on a mobile device. Each aspect of this project is discussed next.

\section{Learning Objects}

Functionally, as Wiley (2000) states, learning objects serve as an instructional design component in e-learning for the development and delivery of educational content. RLO are small digital entities containing instructional media for electronic delivery. Electronic courseware developed for a learning management system, such as Moodle, contain standardized learning objects which may contain digital text, video, audio, and assessment tasks (McGreal, 2004). Furthermore, MoGreal (2004) submits that learning objects serve an educational purpose or learning outcome by being components "in a lesson or assemblage of lessons grouped in units, modules, courses, and even programs" (p. 11). This assertion is supported by Downes (2004) who stipulates that learning objects must be modular and able to be combined and packaged into larger units. For the aggregation of learning objects into larger units to be possible, the property of granularity must be maintained in a learning object (Koper, 2003).

Downes (2004) asserts that learning object repositories (LOR) are what enable discoverability of learning objects. Repositories are collections of learning object metadata in which learning objects can be stored, indexed, and retrieved for reuse.

Standards based LOR are aimed at increasing the effectiveness of both online and blended learning by increasing the sharing, which, in turn, decreases LO development costs (McGreal, 2008). The interoperability of learning objects stored in various repositories has not been fully achieved due to non-standard independent development (McGreal, 2007; 2008), a need addressed by the implementation outlined in this article which demonstrates a repository for standardized learning objects and OER. 


\section{Mobile Device Sensors}

The inclusion of integrated hardware sensors in mobile devices provides the possibility of augmenting learning activities with sensor data. Technology enhanced learning activities, such as those created with the mobile authoring tool in this project, capture spatially distributed physical sensory data, such as video, photos, audio recordings, and GPS locations. Vogel, Spikol, Kurti, and Milrad (2010) state that there are ongoing research challenges related to integrating this collected sensor data to support learning but conclude that "mobile learning can best provide support for learning in context" ( $p$. 65). Thus, the proposed tool must promote capturing contextual experiences via multimedia examples of the environment and their locations. Context is defined as any information illustrating the situation of a learner such as location, time, activities, and surrounding environmental characteristics (Vogel, Spikol, Kurti, \& Milrad, 2010). As a result, the proposed tool will capture a representation of these contextual attributes.

Kuo, Huang, Liu, and Chang (2008) present an implementation of a system using mobile devices for creation of authentic examples. However, their described system does not implement standardization or a method for exporting content beyond the system in which it was created. Herein lies the traditional boundary to reuse. Standardization of content will explore reuse in a multitude of other tools implementing the same standards. Related mobile capture systems do "not provide for learning objects interoperability and reuse with other systems" (Svensson \& Pettersson, 2008, p. 610 ). While the above described systems do create authentic learning and demonstrate mobile learning via sensor data, reuse in multiple contexts is limited. Typically, the contextual and authentic learning examples created within these projects appear to be shared only within the system they were authored for.

IMS Global Learning Consortium Metadata, Content Packaging, and Learning Design specifications were selected as they are well defined and context agnostic. IMS standards are widely implemented within e-learning but are less well developed in mobile learning. Together, these standards permit the creation of metadata, reusable learning objects, and learning activities within a single, portable package.

\section{Metadata}

McGreal (2006) adds that learning objects are educational resources with metadata descriptors for use in technology supported learning. Metadata, or data about data, is essential for addressing implementations of a learning object. Moisey et al. (2006) assert that more comprehensive metadata "enhances the usability of a learning objectthe more complete the metadata, the greater the likelihood that the learning object will be found and reused" (p. 145). Furthermore, Moisey et al. (2006) assert that IEEE LOM is the only standard which has officially been approved for learning object metadata, and Svensson and Pettersson (2008) state that the IEEE LOM is "the most renowned and widely accepted standard to date" (p. 607). 
Specht and Kravcik (2006) present the RAFT project for capturing images and audio in a mobile environment and tagging with metadata. However, content reuse within a learning design or standardized content is not explored. Other implementations that allow for mobile capture and publishing of learning content do not typically reuse the content beyond the system in which it was authored, nor is the capture process integrated (Comas-Quinn, Mardomingo, \& Valentine, 2009; Kiili, Multisilta, Suominen, \& Ketamo, 2010; Volgin, Hung, Vakili, Flinn, \& Shin, 2005).

Several projects implement various types of metadata. Some projects implement an authoring system for metadata such as Learning Resources Metadata Authoring \& Management subsystem of the ASK LDT Project (Sampson, 2005), MEAT: An Authoring Tool for Generating Adaptable Learning Resources (Kuo \& Huang, 2009), Automatically Producing IMS AccessForAll Metadata (Boni, Cenni, Mirri, Muratori, \& Salomoni, 2006), HyCo LOM Editor (Berlanga \& García, 2005), and Reload (Beauvoir, 2011). However, these are not within a mobile context.

While mobile metadata tagging projects have been documented, such as ZoneTag (Ahern et al., 2006), CARDS (Verdejo et al., 2006), GeM Project (Svensson et al., 2010), Mobile Media Metadata (Sarvas, Herrarte, Wilhelm, \& Davis, 2004), Context-Aware Metadata Creation in a Heterogeneous Mobile Environment (Volgin et al., 2005), and Mobile Collector (Kravcik, Kaibel, Specht, \& Terrenghi, 2004), they do not typically implement a widely adopted standardization. Volgin et al. (2005) further support this claim by stating that "contextual metadata gathered in the presented initiatives ends up in a variety of structures, which has an impact on interoperability" (p. 16).

\section{Content Packaging}

The most cited de-facto format of a reusable learning object is that of an IMS Content Package: "IMS Content Packaging is the most widely used learning technology standard in the world" (IMS GLC, 2011b). This standardized format of an RLO enables packaging of instructional content, such as authentic learning objects, to provide aggregation, distribution, and deployment (IMS GLC, 2007). The format permits authors to build learning content that can be easily managed and deployed by learning administrators, interacted with by learners in the runtime environment (IMS GLC, 2007), and provides

the format for exchange of learning objects between systems (IMS GLC, 2011b). The IMS Content Packaging specifications aim to "enable the encapsulation in a concise and easily browsed manner, of all the required content resources, supporting information, and structure required to promote interoperable, online learning experiences" (IMS GLC, 2001, p. 1.1).

\section{Learning Design}

IMS Learning Design (LD) specification supports distributed learning environments (Berlanga \& García, 2005). This specification seeks to meet the following goals, which closely support the aims of OER (Berlanga \& García, 2005). 
- Reproducibility: The playback, runtime, or execution of IMS Learning Design is possible in different settings or contexts, or by different users.

- Interoperability: IMS LD enables exchange and reuse of learning designs across different platforms and courses.

- Compatibility: IMS LD is compatible with other specifications, particularly those published by IMS GLC.

- Reusability: IMS LD provides an identity for each element of learning, decontextualizes it, and exchanges learning elements to permit their reuse in other contexts.

A concept central to IMS LD is that of units of learning (UOL). A UOL is a self contained entity which holds the learning objects and services required in the learning process (Koper \& Olivier, 2004). UOL granularity can vary depending on the objective and may represent a whole course, or a single concept, but contains both the learning resources and learning activities (Stauffer, Lin, \& Koole, 2008) and can be authored completely within the tool described. In this application, a unit of learning can be considered to be an IMS Content Package with the addition of IMS Learning Design which defines activities and related elements.

Koper and Olivier (2004) stipulate that one task leading to adoption of the IMS LD standard is creating authoring tools for different pedagogical and learning development methods. The proposed authoring tool is an implementation, which seeks to satisfy this recommendation. Authoring and editing tools, such as Reload, ASK-LDT (Sampson, 2005), and eXe (eXe, 2011) require non-mobile platforms; thus this represents a limitation for authoring IMS LD in a mobile context. Tools discussed in the next section on authentic learning are designed for capturing authentic learning examples in a mobile context, but do not implement standardization to encourage reuse. Other authoring tools, such as LAMS (Michailidis \& Demetriadis, 2009) and the web-based authoring system by Stauffer et al. (2008), are not fully standards compliant, an impediment for reuse beyond the context the learning design was authored in. Thus, the tool presented authors activities which reference and reuse captured learning objects in a standardized format to enable interoperability.

\section{Authentic Learning}

Authentic learning is an instructional theory focused on learning in context, or real life application of knowledge (Rule, 2006). Rule states that authentic tasks are used to integrate knowledge and skills into life or work settings, via complex activities. Instructional approaches that utilize authentic learning tasks include problem based learning, situated learning, constructive learning environments, and collaborative learning environments (Rule, 2006). This paper presents a tool to capture and create learning activities within these approaches. Mobile device sensor data collection for 
authoring of learning objects created in an authentic context, or authentic learning examples, will be demonstrated in the Methodology section. This content will then be encapsulated in the authentic learning task, described by IMS Learning Design. While the task is authored in a mobile context, the playing or executing of the authentic learning activities can take place in a variety of contexts such as web-based learning or mobile learning. In the past, learning by doing may have been difficult to implement; but technological tools like observation using remote instruments and field work with mobile devices as data collection platforms enables authentic learning experiences (Lombardi, 2007).

An authentic learning example is a subset of reusable learning objects, as previously defined; however, the content contained within an authentic learning example is necessarily captured in an authentic environment. Within the scope of this project, an authentic learning example can be defined as an RLO created in a mobile context in a real life situation, for example, a digital photograph taken with a smart phone of a procedure in a biology laboratory. In addition to the metadata describing a reusable learning object, authentic learning example metadata may be supplemented with location-aware metadata such as a GPS location. Within the proposed implementation, data collected with a mobile device by the authentic learning example authoring tool will be utilized in the activities by the learners without the requirement of being in the authentic location.

Kuo et al. (2008a) present an implementation of a system using mobile devices for creation of authentic examples. This system aims to fulfill the gap in e-learning materials created by a lack of timely, accessible, and well organized examples by providing students a means to create their own examples. Capturing real-world examples using mobile device sensors, appending metadata, and uploading to an elearning platform, allows authentic examples to be created and shared amongst colearners. This platform creates authentic learning objects, however, they are not standardized; the sharing and reuse of the authentic learning examples would be limited to students with access to the same learning platform. This content could not be imported into an LMS or submitted to a standards based repository. Thus, in this context, the previous assertion of an authentic learning example as a subset of reusable learning objects is not well founded. In order for this claim to be supportable, the lack of authentic learning example standardization will be addressed in this project with the use of IMS Content Packaging.

\section{Social Constructionism}

There is a growing influence of constructionism as an approach to learning. However, moving towards a more "authentic" learning environment produced by social constructionism coupled with technology has several challenges. These challenges must be overcome before a paradigm shift resulting from the deconstruction of institutionalism and reconstruction of a social constructionism model can occur. Social constructionism is, in this instance, seen as an extension of authentic learning. 
Authentic learning examples can be captured where and when they occur, and shared under a social constructionism pedagogy in a LMS.

Communications in social constructionism learning are no longer one directional as in traditional instructionalism. Instead, members of the learning community contribute their authentic learning examples to the larger learning enterprise. Computer applications can be used by constructionism theory to create "a computer-based interactive learning environment where the prerequisites are built into the system and where learners can become the active, constructing architects of their own learning" (Sawyer, 2006, p. 40). This project extends this concept beyond computer based learning environments into the mobile learning sphere.

One such technical challenge, and, indeed, an opportunity for innovation, is the ability for a learner to contribute meaningful examples of his or her own learning in a constructionism model. Castillo and Ayala (2008) provide justification for this approach in a mobile context: "The conversational nature of mobile devices and their capabilities to capture and transmit multimedia data (photos, video, audio and texts) make them suitable to collaborative development of learning objects" (p. 55).

In social constructionism, members of the learning group are responsible for introducing new learning objects and activities while the coordinators and mentors act in a support role (Sawyer, 2006). This is precisely the focus of the reusable learning objects, which the tool seeks to create and share. The learning design authored with this tool will support both the learner role and the tutor role and assign learning activities and support activities, respectively.

Providing the proper inclusive medium for this communication to take place is critical to lesson design (J ones, 2006). The focus of bringing cases and real life experiences into content prevents strictly textbook learning, and creates links to experiences the group has undergone. Allowing each learner to exemplify their own experiences creates a wider communal knowledge base which can be shared amongst the group, falling squarely within social constructionism.

Castillo and Ayala (2008) proposed that

when the learner collaborates in the social development of mobile learning objects, he can play two different roles: recorder (record text, voice, audio, still images or video from physical learning environments using mobile devices) or editor (edit these records in such a way that they can be used in learning activities and they can be shared, manipulated, and refined by others). (p. 57)

The recorder role is experienced while capturing authentic learning examples. The editor role is conducted should the author opt to utilize the authentic learning examples 
in a learning design's activities. Using standardized output, both the recorder role and the editor role will provide content that can be "shared, manipulated, and refined by others" (Castillo \&Ayala, 2008, p. 57).

Mobile sensors enable capturing of learning objects in an authentic learning situation. "Mobile devices can be used to collaboratively create, edit and share" learning experiences which specify tasks and roles "based on capture, editing and sharing of audio, photos and texts using a mobile phone" (Castillo \&Ayala, 2008, p. 54). Authoring tools for content capture are identified as a principal component in a mobile learning paradigm (McLean, 2003). Any movement towards social constructionism demonstrates the need for tools in which learners can capture and share learning resources in support of authentic learning. Cleveland-Innes et al. (2005, p. 380) maintain that "learning object creation, tagging, storing and retrieving must be learner centered."

Thus, the research goals are as follows:

1. to demonstrate mobile device sensor data used to author authentic learning examples for use in reusable learning objects/ open educational resources;

2. to utilize learning objects created in a mobile context to author learning designs conforming to IMS standards;

3. to permit sharing of authentically authored learning content and learning designs across contextual boundaries.

These research questions are reflected in the conceptual design (Figure 1) of the tool. Learners could use the tool to capture learning examples from their daily life and share with co-learners in a learning management system or runtime environment. Instructional designers could create authentic learning examples as the basis for authoring learning activities. 


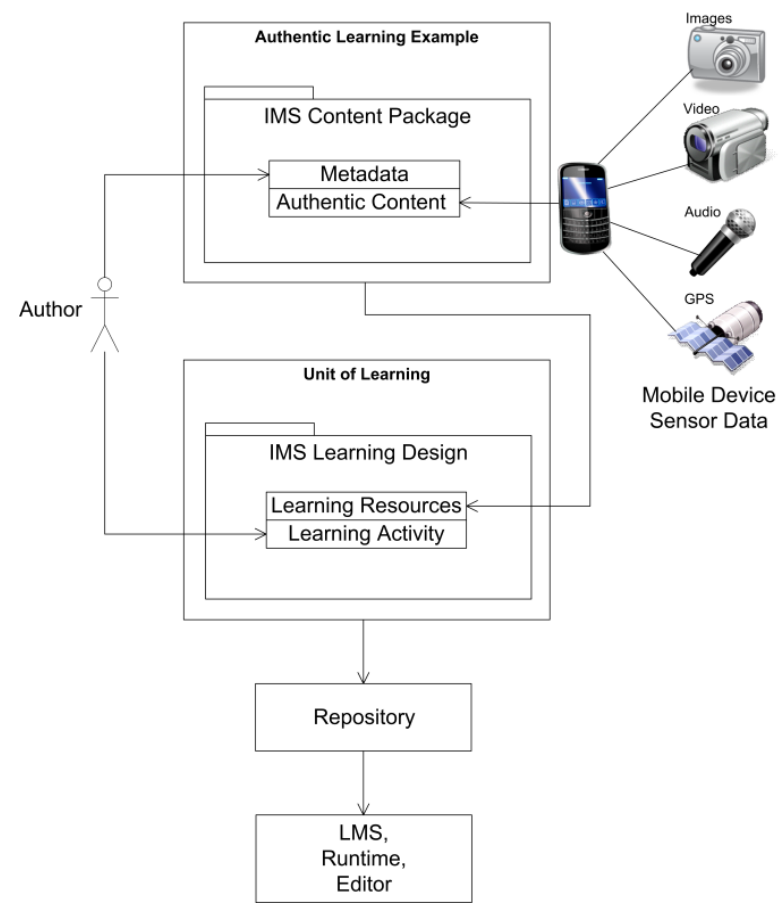

Figure 1. Conceptual design of the mobile authentic authoring tool.

\section{System Architecture}

In order to achieve the task of creating IMS standard learning objects in a mobile context, the implementation solution is a two-tier application consisting of a mobile client and a server component. This architecture compiles the content on the server, which automatically shares content in the repository, and avoids the situation where the content would only exist on the mobile device. A mobile application without a server component would require explicit and manual effort to upload the learning content to a repository for sharing with others.

\section{Mobile component.}

The resulting solution is a mobile application, entitled "MAAIMS", which is an acronym for Mobile Authentic Authoring in IMS. The MAAIMS client runs on a smart phone, with current implementation focused on Research in Motion devices with Blackberry OS 5, 6, or 7 installed.

The component in the mobile device runs on top of the operating system. The mobile platform allows multitasking so the MAAIMS application can be always-on, running in the background, until the user comes across an authentic learning situation he/she wishes to capture.

This component presents the user interface and interacts with the hardware mobile device sensors and IO channels, such as the touch screen, keyboard, the global 
positioning sensor, the embedded camera, and the microphone. Functionality like authentic learning example capture necessitates this subset of sensors to be present on the mobile hardware.

The mobile client connects to a server for uploading metadata and authentic learning content, and subsequently for downloading the resulting content package to local storage on the mobile device. By default, this ensures that learning content is stored on the server, which acts as a repository. However, it necessitates that the mobile device is connected to the Internet for the duration of the application execution. Given the rapid proliferation of 3G and 4G mobile data networks, along with Wi-Fi coverage increasing all the time, the connectivity requirement of this application was deemed an acceptable requirement.

GPS coordinates are used to individually tag authentic learning examples with their capture location. MAAIMS is designed to capture real-life learning examples, such as fieldwork demonstrations. Thus, outdoor examples which are location dependent can be geo-tagged. Learners could thereby visit a location of a learning example, or location data could enable adaptive learning at runtime wherein content is conditionally presented depending on learner location.

\section{Server component.}

The server interfaces with the mobile client over standard HTTP and TCP/IP protocol. The server component accepts the metadata and multimedia uploaded by the client, stores it in a database, and then dynamically generates HTML (environments, activities, objective, prerequisite, and resources) and XML (imsmanifest.xml) according to the IMS standards, and bundles generated content and multimedia into a package interchange file.

The package interchange file is a uniquely named .zip file that contains all of the learning resource HTML files, the imsmanifest.xml, and the captured multimedia files representing authentic learning objects. The zip file is stored on the server for the mobile client to download to local storage and a copy is retained on the server in the web-based repository for reuse.

\section{Methodology}

This methodology subscribes to the design for Learning Design authoring tools developed by Boticario and Santos (2007). Course materials should be developed as a set of learning objects as the first step in an IMS LD authoring tool. Secondly, metadata should be added to those learning objects. Finally, the published methodology states that instructional design should be added next. 


\section{Collect Learning Object Metadata}

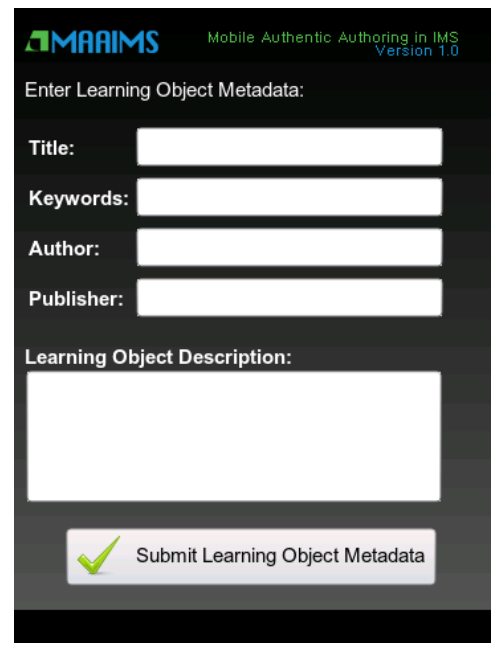

(a)

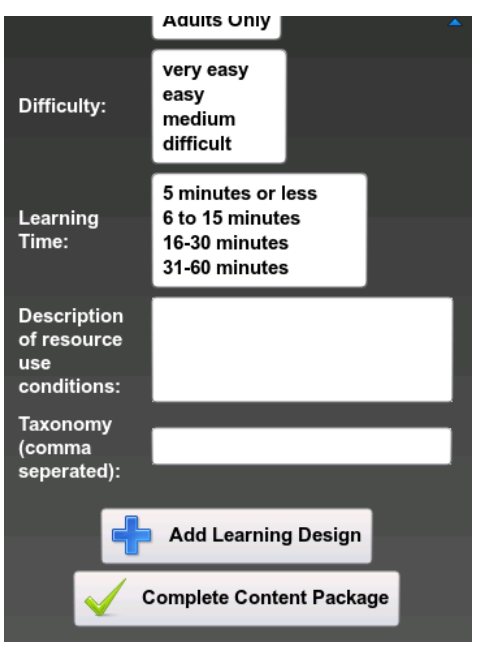

(b)

Figure 2. RLO metadata collection in MAAIMS: (a) represents general metadata and (b) collects educational metadata.

The metadata fields collected follow the IMS Metadata specifications based on the IEEE/ LOM Metadata. Figure 2(a) shows the initial screenshot of the mobile component where IMS Metadata is collected which represents the general and lifecycle elements. This metadata "groups information describing learning object as a whole" (IMS GLC, 2001b).

The technical section describes the technical contents of the resources in the content package. This includes requirements to view the content at runtime, file types included in the package, and the location at which the content package is available. Wherever possible, metadata is application generated to minimize user input. Furthermore, other metadata elements fields can be assumed to be constants, such as the rights section which specifies the conditions of use of content package (IMS GLC, 2001b). By default, all content produced with MAAIMS is free of cost and copyright; thus these XML element values are set by the application to maximize content reuse. MAAIMS metadata could also include a Creative Commons license which would limit content reuse to individuals and educational institutions or organizations not seeking to commercialize the content, all while retaining attribution rights.

In Figure 2(b), the educational metadata is presented after the collection of authentic learning examples because the responses to fields such as typical learning time will depend on the content, number, and type of the learning examples collected. This metadata represents the "educational or pedagogic features of the learning object" (IMS GLC, 2001b). 


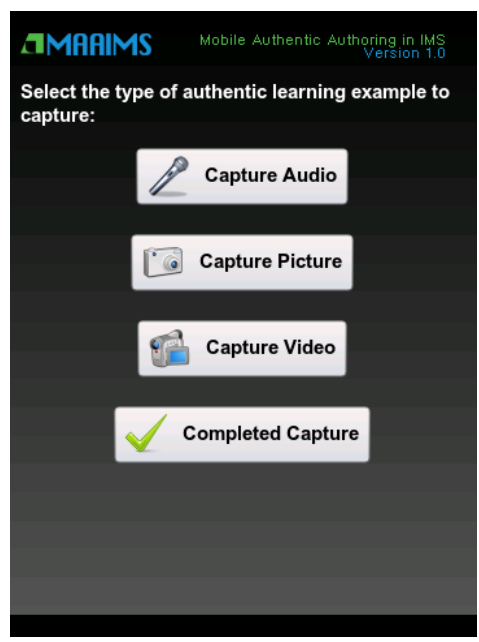

(a)

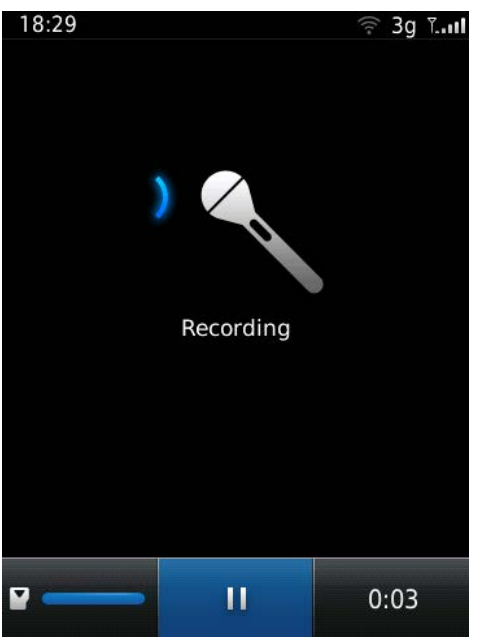

(b)

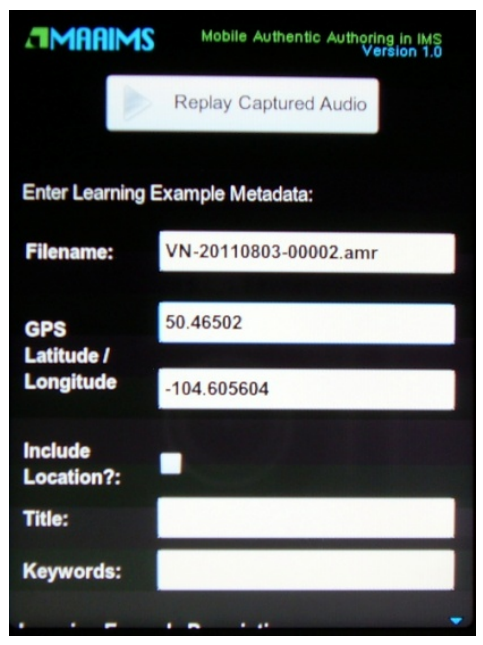

(c)

Figure 3. The authentic learning example capture process: (a) shows the selection of media type, (b) displays the capture, and (c) shows the captured filename, location, and example description.

\section{Collect Authentic Learning Examples}

Key to this project is the use of mobile sensors to capture authentic learning examples. The MAAIMS application achieves this task by integrating with the native applications of the mobile device for three mediums of media capture. GPS location and learning example description are also independently obtained for each example.

Figure 3(a) is presented after the initial learning object metadata has been submitted. It presents options for each type of authentic learning example. If the user selects "Capture Audio," the application will launch the audio recording application, as shown in Figure 3(b). Similarly, the camera application will launch if the "Capture Picture" option is selected and the video camera application will launch if "Capture Video" is selected. The user can then capture the authentic learning example by recording an authentic learning scenario. The GPS coordinates are queried simultaneously as each authentic learning example is captured.

Figure 3(c) displays the description collection for each authentic learning example. The filename field and latitude/longitude fields are auto-filled by the application, and cannot be overwritten by the user. The location fields are only available if the mobile device was able to receive GPS coordinates.

Once a suitable capture has been completed and the required metadata has been entered, the user can press submit the metadata and multimedia. This uploads the media to 
binary file storage on the web server, and the corresponding example metadata to the database.

\section{Complete Content Package without Learning Design}

Once the completed capture option has been selected, the application collects educational metadata as previously discussed. Prior to submitting the educational metadata, the user is presented with two options, as seen in Figure 2(b). "Add Learning Design" will create learning activity within the content package, and "Complete Content Package" will complete the content package without embedded learning design. If the user opts to complete the content package, the server generates the physical files (actual media representing authentic learning objects) and the manifest (containing the metadata, resources, and organizations sections), which are created and compiled into a standalone package, and then shared to the repository.

\section{Add. Optional Learning Design}

This step displays how to create a content package including IMS Learning Design Level A. Figure 2(b) shows the educational metadata collection screen's options. Pressing the "Add Learning Design" button will direct the program flow as this step details.

The IMS Learning Design information model specifies title, learning-objectives, and prerequisites as learning design elements, which are collected, as shown in Figure 4(a).

The learning objective field represents the overall goals to be met by learners who complete the activities in the learning design and the authentic learning examples contained in the content package. MAAIMS defines the learning objective at the global level and not on each activity.

Next, Figure 4(a) requests the user input prerequisites. Previously captured authentic learning objects can also be tagged as a prerequisite to the unit of learning. The check box representing each of the previously captured learning examples can be selected if the example specifies one of the entry requirements for interacting with the learning design.

Activities can be added to an act as shown in Figure 4(b). Pressing the "Add Learner Activity" button will create a new activity, assigned to the learner role, in the current act.

The "Add Tutor Activity" button will perform the same function, but the tutor role will be assigned, as shown in Figure 4(c). Activities can also be created with an environment, which creates a relationship between the activity and an environment within which the activity is executed. An environment is a learning object, service, or tool which is available to the learner at runtime, and the type is set by the author as seen in the drop down selection of Figure 4(c). 


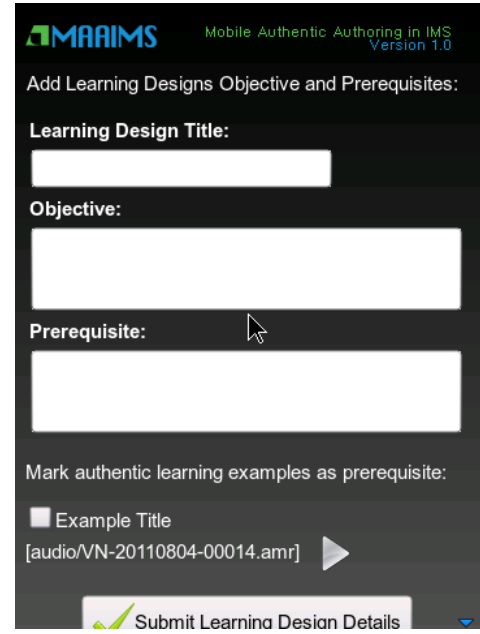

(a)

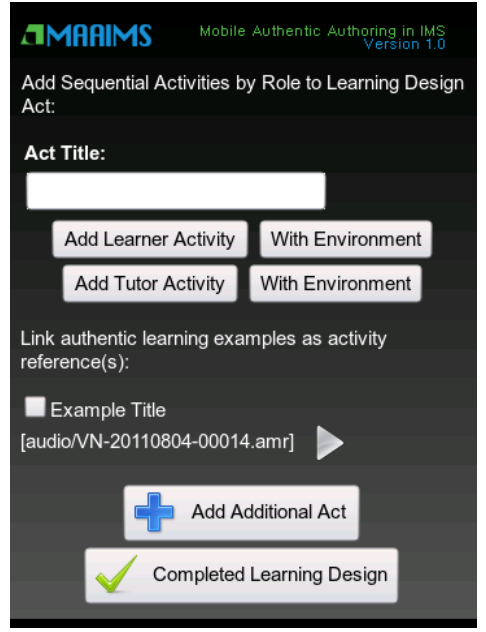

(b)

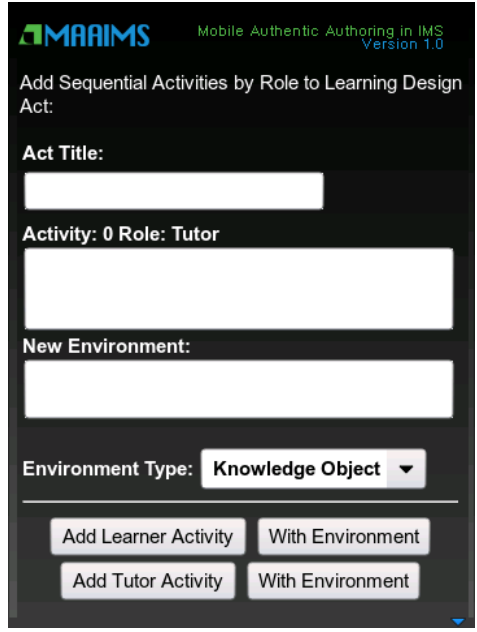

(c)

Figure 4. Learning Design objectives and prerequisites are created in (a), (b) shows new activities created within acts, and authentic learning examples tagged as references, and (c) displays activities created with an environment.

Previously created authentic learning examples can be referenced within an act in a similar manner to how they are referenced as a prerequisite. If an authentic learning example is referenced within an act, it would be considered a relevant learning object to the activities contained within the act. It would be treated as reference material for completing the activities defined.

After all activities have been entered into the current act, two options are given to the user, as shown in Figure 4(b): "Add Additional Act" and "Completed Learning Design." The add additional act option will insert another act into the learning design, and will repeat the process of adding activities, environments, and referencing authentic learning examples. As many acts can be added as the author deems necessary to meet the defined learning objective.

Once the learning design has been completed, the package interchange file, including learning design, is generated by the server which can be accessed from the mobile client or the repository.

This methodology demonstrates that mobile device sensor data can be utilized to author authentic learning examples. These authentic learning examples are, in turn, utilized within IMS Content Packages and IMS Learning Designs. The MAAIMS implementation indicates that a mobile application can complete these tasks in a mobile context. A video demonstration of an authoring scenario can be viewed at http:// goo.gl/ eaVqd. 


\section{Results}

The remaining research goal is to share the created content packages in other contexts beyond the mobile platform in which they were authored. This goal seeks to demonstrate the reusability and applications of MAAIMS output since OER are required to be able to be repurposed by others.

\section{Repository}

Repositories are collections of learning object metadata in which learning objects can be stored, indexed, and retrieved for reuse; thus a repository is required to address the sharing and reuse research goal.

Figure 5 displays the MAAIMS repository, containing each package interchange file created by MAAIMS.

\section{Validation}

To confirm that the learning design produced by MAAIMS is compliant to the standards, CopperCore Version 3.3 is used to validate the package interchange file. A .zip file, from the MAAIMS repository or stored locally on the mobile device, can be input into CopperCore for validation. The validation engine checks the XML compliance against the schema, meaning that the imsmanifest.xml file is both valid and wellformed, ensures that the content is properly referenced, and the learning design is semantically correct. A successful validation of the learning design supports the assertion that MAAIMS can produce valid IMS Learning Designs in a mobile context. 


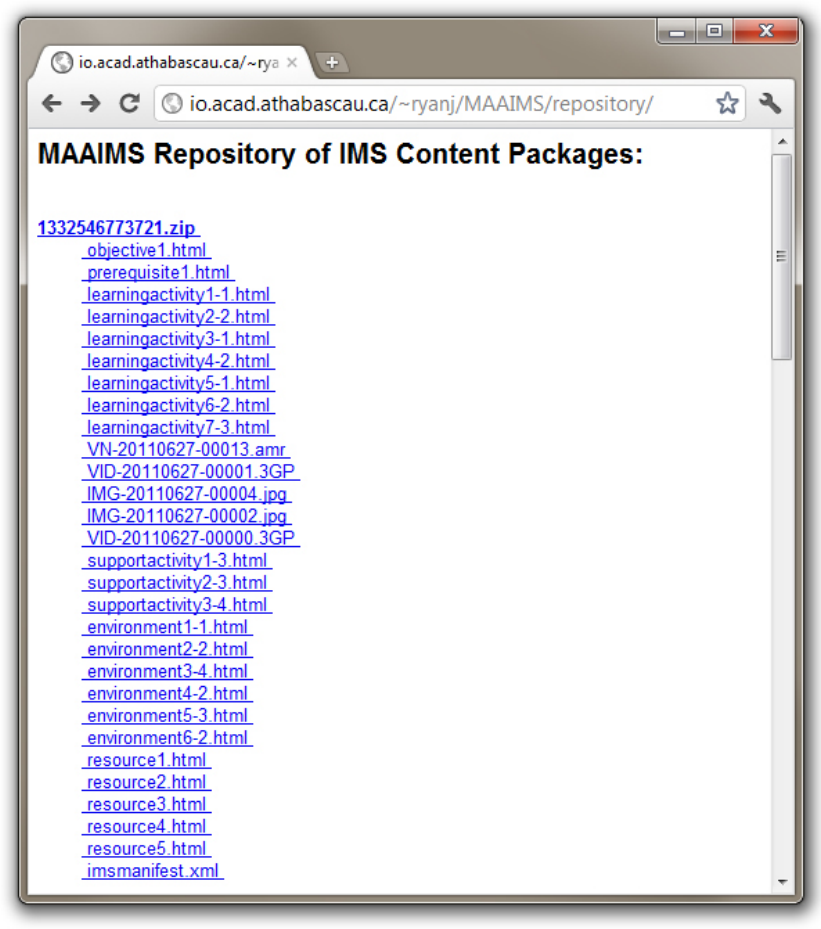

Figure 5. A MAAIMS repository entry of a content package containing a learning design. The uppermost .zip file is the content package which contains the learning contents and learning design. This represents a single unit of learning which could be imported into other systems, such as an editor or LMS.

\section{Learning Management Systems (LMS)}

Key to the reuse of MAAIMS created content is importing into an LMS which can deliver web-based learning for distance education, continuing education, or blended classrooms. Many LMSs implement compatibility with SCORM or IMS standards. Using various LMSs, it is demonstrated that MAAIMS produces content compatible for use outside of the MAAIMS authoring environment. Thus, authentic learning examples will be able to be shared with learners using an LMS.

It remains important to import IMS Learning Design in an LMS to demonstrate MAAIMS content in an e-learning context. For this demonstration, an LMS called dotLRN is used. "Regarding its functionality, it is strongly compliant with educational standards for courses delivery (IMS-LD, IMS-CP, IMS-MD) (Munoz, 2007, p. 240)", which align with the standards MAAIMS utilizes for authoring.

The package interchange file can be imported from the repository and LMS users can be assigned to the roles in the LD. A new instance of the learning design runtime can then be created and executed. 
All MAAIMS created IMS Learning Design elements, such as activities, roles, environments, authentic learning examples as resources, prerequisites, and objectives are successfully processed at runtime in the dotLRN LMS. This demonstrates MAAIMS authentic learning examples and learning design reuse in an LMS.

\section{Findings}

"Open educational resources include full courses, course materials, modules, textbooks, streaming videos, tests, software, and any other tools, materials, or techniques used to support access to knowledge" (Atkins et al., 2007, p. 4). Since OER can include full courses or modules, MAAIMS authored modules, or units of learning, could be aggregated into a full course to satisfy this most comprehensive definition. Learnergenerated course materials could be developed with this tool, which could include video or other multimedia samples. Learning design can be employed within the tool to create activities which could form the basis of evaluation. In fact, the MAAIMS tool, or the software itself, fits within the scope of this OER definition, rather than just the resulting RLO output.

The tools used to test MAAIMS produced content were limited to a subset which met selected criteria. To be considered for testing, functionality must be available to import IMS Content Packages or IMS Learning Design and the tool must be publicly available.

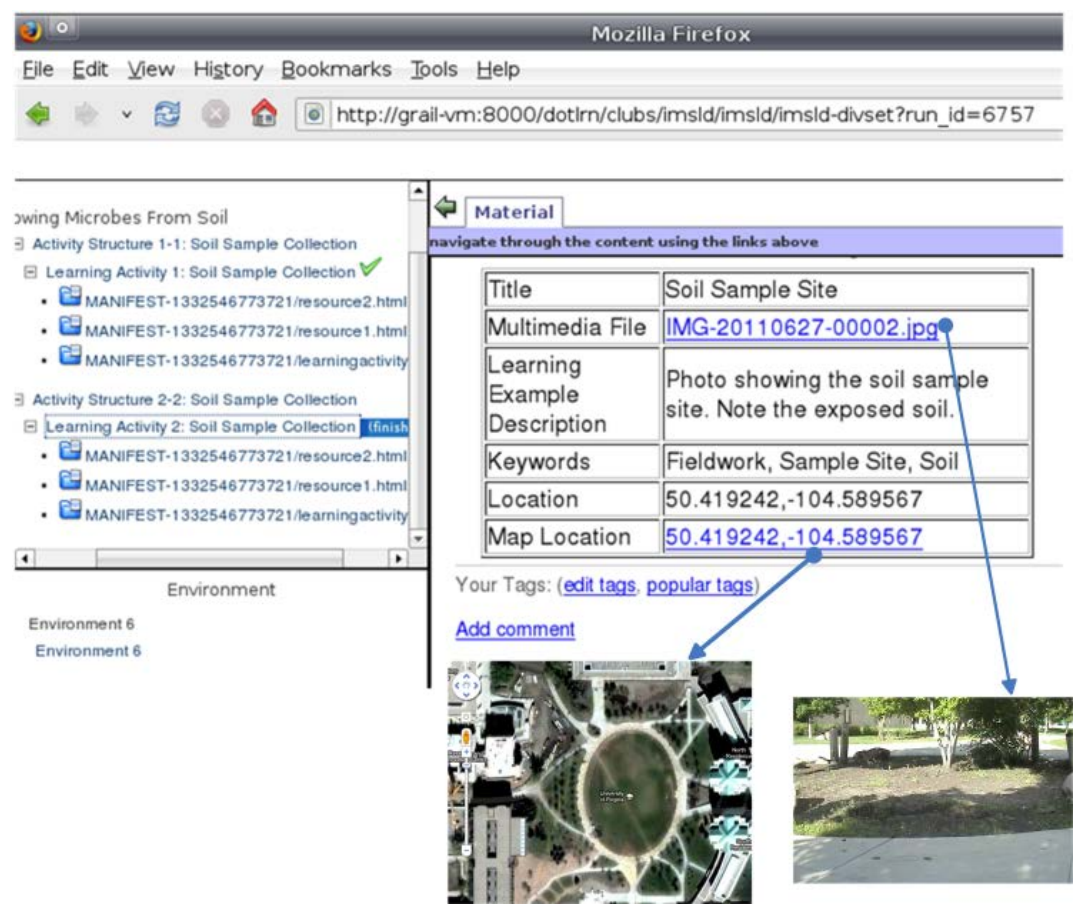

Figure 6. A MAAIMS authored learning design in an LMS. An authentic learning example and the location it was captured are accessible via hyperlink. 
Moodle's prevalence in the education sector positions this LMS as the target test platform for MAAIMS units of learning. However, this was not possible as the community has not developed an integrated import implementation for IMS LD, despite prior plans indicating the contrary. However, players such as SLeD, CopperCore Player, and Reload Learning Design Player can effectively be linked as an external resource to Moodle. The URL of the player is added as an external resource, and the unit of learning can be played within the learner's browser. Berggren et al. (2005) have proven this to be a practical solution to the lack of embedded Moodle LD runtime. Typically, there is additional overhead with this configuration; for example, an additional web server and database are required. Moreover, the results of the learning design, such as a particular learner completing the unit of learning, are not integrated into the LMS. Role management is also handled separately; users must be assigned roles within the LD player, instead of selecting users already present in the LMS.

There is a parallel between the concepts contained within MAAIMS and other mobile applications, such as using smart phones as sensors. For example, capturing photos of friends and uploading to Facebook using a mobile application is similar to capturing a photo with MAAIMS and uploading to a repository. The concept of metadata is similar to tagging a friend in a photo on Facebook - simply augmenting captured multimedia with further descriptive information. Mobile applications can capture video and upload to YouTube, a process similar to capturing authentic learning example videos and sharing as learning content. Moreover, mobile applications like Foursquare's functionality of geolocation and location based services are similar to those in MAAIMS. Experience with these similar mobile application functionalities should help users understand the concepts when applied to learning content.

Testing with various platforms revealed that editing and runtime environments typically do not have native players installed that are required to view all types of authentic learning content.

As a result, future exploration into integrating authentic learning example multimedia from MAAIMS into a streaming service such as YouTube may be warranted. This would allow content packages to refer to the authentic learning examples as external resources and reduce package interchange file sizes, which were a problem for some LMS systems.

Initial testing was completed with Moodle, in a mobile context, using MAAIMS content packages containing authentic learning examples. This allows learning content authoring to be completed in a mobile context and learning content sharing and playback to be completed in a mobile context. This conceptually demonstrates a set of fully mobile learning tools which complete the mobile learning cycle wherein learning content authoring (design time) and playback (runtime) occur in a mobile context. Further testing is required with SMILE PDA Learning Design Player as a mobile runtime environment using MAAIMS content. 


\section{Conclusion}

This article presented MAAIMS, a mobile authoring tool for standardized learning content. MAAIMS' novelty stems from the smooth transition and integration between metadata collection, authentic learning example collection, and learning design authoring. The tool demonstrated authoring of authentic learning examples with mobile sensors and location-awareness in a mobile context, and utilization of the authentic learning examples in IMS Metadata, IMS Content Package, and IMS Learning Design. The standardized output permits the content to be reused in other platforms and contexts as a reusable type of OER, a reusable learning object. Content is shareable via the repository, is validated against the standards, and is reusable in multiple contexts, editing tools, runtime environments, and learning management systems. The adoption of OER necessitates authoring tools to create digital assets like learning objects. MAAIMS provides a method for open education resource creation in a mobile context, and sharing in a social constructivism pedagogy. 


\section{References}

Ahern, S., Davis, M., Eckles, D., King, S., Naaman, M., Nair, R., Mirjana, S., et al. (2006). ZoneTag: Designing context-aware mobile media capture to increase participation. Proceedings of the Pervasive Image Capture and Sharing: New Social Practices and Implications for Technology Workshop (PICS 2006). Presented at the Eighth International Conference on Ubiquitous Computing.

Atkins, D., Brown, J., \&Hammond, A. (2007). A review of the open educational resources (OER) movement: Achievements, challenges, and new opportunities. Menlo Park, CA: The William and Flora Hewlett Foundation.

Beauvoir, P. (2011, 05). RELOAD Project. Retrieved from http:// www.reload.ac.uk/

Berggren, A., Burgos, D., Fontana, J ., Hinkelman, D., Hung, V., Hursh, A., \& Tielemans, G. (2005). Practical and pedagogical issues for teacher adoption of IMS learning design standards in Moodle LMS. J ournal Of Interactive Media In Education, 1. Retrieved from http://jime.open.ac.uk/article/2005-2/264

Berlanga, A. J ., \& García, F. J . (2005). Authoring tools for adaptive learning designs in computer-based education. Proceedings of the 2005 Latin American conference on Human-computer interaction (pp. 190-201).

Boni, M., Cenni, S., Mirri, S., Muratori, L. A., \& Salomoni, P. (2006). Automatically producing IMS AccessForAll Metadata. Proceedings of the 2006 international cross-disciplinary workshop on Web accessibility (W4A): Building the mobile web: rediscovering accessibility? (pp. 92-97).

Boticario, J . G., \& Santos, O. C. (2007). An open IMS-based user modelling approach for developing adaptive learning management systems. J ournal of Interactive Media in Education, 2.

Castillo, S., \& Ayala, G. (2008). ARMOLEO: An architecture for mobile learning objects. Electronics, Communications and Computers, 2008. CONIELECOMP 2008, 18th International Conference on (pp. 53- 58). Washington, DC: IEEE Computer Society.

Chu, H. C., Hwang, G. J ., \& Tseng, J . C. R. (2010). An innovative approach for developing and employing electronic libraries to support context-aware ubiquitous learning. The Electronic Library, 28(6), 873- 890.

Cleveland-Innes, M., McGreal, R., Anderson, T., Friesen, N., Ally, M., Tin, T., Graham, R., et al. (2005). The Athabasca University eduSource Project: Building an accessible learning object repository. Australasian J ournal of Educational Technology, 21(3), 367-381. 
Comas-Quinn, A., Mardomingo, R., \& Valentine, C. (2009). Mobile blogs in language learning: Making the most of informal and situated learning opportunities. ReCALL, 21(1), 96- 112.

Conole, G., \&Weller, M. (2008). Using learning design as a framework for supporting the design and reuse of OER. J ournal of Interactive Media in Education, 2008(1).

Downes, S. (2007). Models for sustainable open educational resources. Interdisciplinary J ournal of Knowledge and Learning Objects, 3.

Downes, S. (2004). Learning objects: Resources for learning worldwide. In R. McGreal (Ed.), Online education using learning objects. London: Routledge/ Falmer.

eXe (2011). eXe eXeLearning. Retrieved from http:// exelearning.org/

Friesen, N. (2009). Open educational resources: New possibilities for change and sustainability. The International Review of Research in Open and Distance Learning, 10(5).

Gonzalez-Barbone, V., \&Anido-Rifon, L. (2008). Creating the first SCORM object. Computers \&Education, 51(4), 1634- 1647.

Griffiths, D., Beauvoir, P., Liber, O., \& Barrett-Baxendale, M. (2009). From reload to ReCourse: Learning from IMS learning design implementations. Distance Education, 30(2), 201-222.

Hsu, T. Y., \& Chen, C. M. (2010). A mobile learning module for high school fieldwork. J ournal of Geography, 109(4), 9.

IMS GLC. (2001a). IMS Content Packaging best practice guide. Retrieved from http:// www.imsglobal.org/content/packaging/cpv1p1p2/imscp bestv1p1p2.ht $\underline{\mathrm{ml}}$

IMS GLC. (2001b). IMS Learning Resource meta-data information model. Retrieved from http:// www.imsglobal.org/metadata/imsmdv1p2p1/imsmd_infov1p2p1.html

IMS GLC. (2007). IMS Content Packaging v1.2 best practice and implementation guide. Retrieved from http:// www.imsglobal.org/ content/packaging/ cpv1p2pd2/imscp_bestv1p2pd2. $\underline{\mathrm{html}}$

IMS GLC. (2011a). IMS GLC: IMS Inteoperability Project Groups. Retrieved from http://www.imsglobal.org/ interoperabilitygroups.html 
IMS GLC. (2011b). IMS Global Learning Consortium. Retrieved from http:// www.imsglobal.org/ interoperabilitygroups.html

J ones, S. (2006). Using IT to augment authentic learning environments. Authentic learning environments in higher education (pp. 172- 181). Hershey, PA: Idea Group.

Kiili, K., Multisilta, J ., Suominen, M., \& Ketamo, H. (2010). Learning experiences of mobile social media. International J ournal of Mobile Learning and Organisation, 4(4), 346- 359.

Koper, R. (2003). Combining reusable learning resources and services with pedagogical purposeful units of learning. Reusing online resources: A sustainable approach to e-learning (pp. 46- 59). London, UK: Kogan Page.

Koper, R., \& Olivier, B. (2004). Representing the learning design of units of learning. Educational Technology \&Society, 7(3), 97- 111.

Kravcik, M., Kaibel, A., Specht, M., \& Terrenghi, L. (2004). Mobile collector for field trips. Educational Technology and Society, 7, 25-33.

Kuo, Y. H., \&Huang, Y. M. (2009). MEAT: An authoring tool for generating adaptable learning resources. Educational Technology \& Society, 12(2), 51- 68.

Kuo, Y. H., Huang, Y. M., Liu, T. C., \& Chang, M. (2008). Collaborative creation of authentic examples with location for u-learning. Proc. e-Learning, 2, 16- 20.

Lombardi, M. M. (2007). Authentic learning for the 21st century: An overview. Educause learning initiative, 1, 1- 7.

McGreal, R. (2004). Learning objects: A practical definition. International J ournal of Instructional Technology and Distance Learning, 1(9), 21.

McGreal, R. (2006). Implementing learning object metadata for mobile devices using CanCore. Presented at the Advanced International Conference on Telecommunications and International Conference on Internet and Web Applications and Services, Guadeloupe, French Caribbean.

McGreal, R. (2008). A typology of learning object repositories. Handbook on information technologies for education and training (pp. 5- 28). Heidelberg, Germany: Springer.

McLean, N. (2003). The m-learning paradigm: An overview (A Report for the Royal Academy of Engineering and the Vodafone Group Foundation). Retrieved from http://pttmedia.com/newmedia knowhow/KnowHow Design/Instructional Design/iMobile/mlearning.rtf 
Michailidis, N. P., \& Demetriadis, S. N. (2009). Technology tools for scripted collaborative learning: The case of the Reload Learning Design Player. Proceedings of the Fourth Balkan Conference in Infomatics (pp. 163-168). Washington, DC, USA: IEEE Computer Society.

Moisey, S. D., Ally, M., \& Spencer, B. (2006). Factors affecting the development and use of learning objects. The American J ournal of Distance Education, 20(3), 143161.

Munoz, O. R. (2007). Accessibility requirements for educational packages in dotLRN. Proceedings of the FLOSS (Free/ Libre/ Open Source Systems) International Conference 2007 (p. 240). J erez de la Frontera, Spain.

Nakabayashi, K. (2009). Design and implementation of multiplatform mobile-learning environment as an extension of SCORM 2004 Specifications. In Multiplatform e-learning systems and technologies: Mobile devices for ubiquitous ICT-based education (pp. 164-181). Hershey, PA: IGI Global.

Ogata, H. (2008). Computer supported ubiquitous learning: Augmenting learning experiences in the real world. Wireless, Mobile, and Ubiquitous Technology in Education, 2008. WMUTE 2008. Fifth IEEE International Conference (pp. 310).

Pettersson, O., \& Gil, D. (2010). On the issue of reusability and adaptability in mlearning systems. Wireless, Mobile, and Ubiqitious Technologies in Education, IEEE (pp. 161-165). doi:10.1109/WMUTE.2010.48

Rule, A. (2006). The components of authentic learning. J ournal of Authentic Learning, 3(1), 1- 10 .

Sampson, D. (2005). Towards next generation activity-based web-based educational systems. Proceedings of the Fifth IEEE International Conference on Advanced Learning Technologies (pp. 868-872).

Sarvas, R., Herrarte, E., Wilhelm, A., \& Davis, M. (2004). Metadata creation system for mobile images. Proceedings of the 2nd international conference on Mobile systems, applications, and services (pp. 36-48).

Sawyer, R. K. (2006). The Cambridge handbook of the learning sciences. Cambridge University Press.

Specht, M., \& Kravcik, M. (2006). Authoring of learning objects in context. International J ournal on E-Learning, 5(1), 25. 
Stauffer, K., Lin, F., \& Koole, M. (2008). A methodology for developing learning objects for web course delivery. International J ournal of Distance Education Technologies, 6(3), 58.

Svensson, M., \& Pettersson, O. (2008). Making use of user-generated content and contextual metadata collected during ubiquitous learning activities. Eighth IEEE International Conference on Advanced Learning Technologies (pp. 606610). IEEE. doi:10.1109/ICALT.2008.169

Svensson, M., Kurti, A., \& Milrad, M. (2010). Enhancing emerging learning objects with contextual metadata using the linked data approach. The 6th IEEE International Conference on Wireless, Mobile, and Ubiquitous Technologies in Education (pp. 50-56).

Téllez, A. G. (2010). Authoring environment for e-learning production based on independent XML formats. Education Engineering (EDUCON), 2010 IEEE (pp. 415-422).

Verdejo, M. F., Celorrio, C., \&Lorenzo, E. J . (2006). Improving learning object description mechanisms to support an integrated framework for ubiquitous learning scenarios. Fourth IEEE International Workshop on Wireless, Mobile and Ubiquitous Technology in Education (pp. 93-97). Los Alamitos, CA: IEEE Computer Society.

Vogel, B., Spikol, D., Kurti, A., \& Milrad, M. (2010). Integrating mobile, web and sensory technologies to support inquiry-based science learning. Wireless, Mobile, and Ubiquitous Technologies in Education, IEEE (pp. 65-72). doi:10.1109/WMUTE.2010.41

Volgin, O., Hung, W., Vakili, C., Flinn, J ., \& Shin, K. G. (2005b). Context-aware metadata creation in a heterogeneous mobile environment. Proceedings of the international workshop on Network and operating systems support for digital audio and video (pp. 75- 80).

Wiley, D. A. (2000). Connecting learning objects to instructional design theory: A definition, a metaphor, and a taxonomy. Learning Technology, 2830(435), 135 .

Yang, J . T. D., Chiu, C. H., Tsai, C. Y., \&Wu, T. H. (2004). Visualized online simple sequencing authoring tool for SCORM-compliant content package. Advanced Learning Technologies, 2004. Proceedings IEEE International Conference on (pp. 609-613).

Zualkernan, I. A., Nikkhah, S., \&Al-Sabah, M. (2009). A lightweight distributed implementation of IMS LD on Google's Android platform. 2009 Ninth IEEE International Conference on Advanced Learning Technologies (pp. 59-63). 


\section{Athabasca University $\mathbf{I}$}

(c) 